\title{
INTRODUCTION TO THE SPECIAL ISSUE ON BLENDED LEARNING
}

\author{
Anthony G. Picciano \\ Associate Editor, JALN \\ In April 2008, the University of Illinois-Chicago hosted the Fifth Sloan-C Workshop on Blended Learning \\ and Higher Education. This workshop attracted 180 educational leaders, faculty members, instructional \\ designers and researchers who discussed, shared and considered effective practices in the design and \\ delivery of blended learning environments. Presentations on best practices, lessons learned, and research \\ on the phenomenon of blended learning stoked the discussion for two days.
}

The theme of the workshop, Blending with Purpose, attempted to focus the discussions on the importance of designing blended learning courses and programs with specific educational goals and objectives in mind. The theme developed out of a growing concern that many faculty were using the latest technology simply for the sake of the using technology without carefully considering the pedagogical benefits and "purpose". The organizing committee for the workshop also understood that blended learning was not just a faculty-driven activity but needed support and guidance from administration and instructional designers. As a result, three areas of focus helped organize the workshop activities namely: administration, pedagogy, and evaluation/assessment.

The administrative focus of the workshop centered on developing strategic and purposeful approaches to blended learning that related to an institutional visions and long-range plans. As all administrators, department heads and program directors who have tried to juggle competing priorities over scarce resources know, implementing a blended learning initiative without considering all stakeholders or having a clear vision and concrete objectives is an effort doomed to failure. As obstacles emerge-and they always do-following the institution's roadmap keeps the blended learning initiative focused on the mission and goals and provides a means to assess progress.

The pedagogical focus of the workshop looked to specifics of improving instruction. Sessions were designed to examine new ways to present content, improve student communication, actively engage students, design assessments, and provide "real" world and service learning experiences for students. Blended learning was discussed as a way to provide students with more flexibility in learning, more opportunities to practice what they are learning, and more time for reflection.

The workshop's third focus concentrated on the ever growing issues and practices related to evaluation and assessment. How do stakeholders evaluate and assess the impact of blended learning on the institution as well as on learning? Discussions centered on evaluation models that reflect blended learning's impact on the institution, the students, and the instructors as well as on the need to develop new outcome models. Assessment considerations focused specifically on how student learning is moving from objective, nonauthentic and non-contextual practices to models that reflect interpretive, authentic and contextual approaches.

The seven articles selected for this special edition reflect some of the most important issues presented at the Sloan-C Workshop. The first article by Anthony Picciano provides background on the theme of the workshop, Blending with Purpose, and recommends that instruction be designed to meet the needs of a 
variety of learners. Specifically, Blending with Purpose: The Multimodal Model recognizes that because learners represent different generations, different personality types, and different learning styles, teachers and instructional designers should seek to use multiple approaches including face-to-face methods and online technologies that meet the needs of a wide spectrum of students. Critical to this model is the concept that academic program and course goals and objectives drive the pedagogical approaches and technologies used.

Mary Niemiec and George Otte in An Administrator's Guide to the Whys and Hows of Blended Learning provide insightful advice on the importance of administrative attention to blended learning. This article points out the institutional benefits as well as the institutional challenges related to the integration of online and on-campus instruction. The reasons for engaging in blended learning determine how things will play out, so the why is given precedence over the how. Nevertheless, there is an attempt to elaborate the methods even more extensively than the reasons and to drill down into the issues that must be taken into account in any successful implementation. How the details sort out necessarily varies from one institution to the next, but there are certain considerations that seem genuinely indispensable, and are the keys to success or failure, sustainability or aborted effort.

David Larson and Chung-Hsien Sung in Comparing Student Performance: Online versus Blended versus Face-to-Face, report on a three way comparison of delivery modes in an introductory Management Information Systems course. The purpose of the study was to determine if there existed a difference in student success among the delivery modes. The research compares student exam and final grade results in a course that was taught by the same instructor using face-to-face, blended, and online delivery modes. Additionally, a discussion of this course in relation to student satisfaction, learning effectiveness, and faculty satisfaction is presented. Their research found no significant difference among delivery modes. Additionally, blended and online modes did very well when measuring student satisfaction, learning effectiveness, and faculty satisfaction.

The next article, A Case Study from Golden Gate University: Using Course Objectives to Facilitate Blended Learning in Shortened Courses, discusses utilizing course objectives to drive the change of existing 10-15 week undergraduate courses into 8 week courses that feature blended learning tools. Bob Fulkerth provides first-hand insights on how to design faculty and instructional development programs by stressing the importance of examining purposes and pedagogical goals. This article reflects his years of experience in leading faculty to adopt technology within the context of meaningful pedagogy.

Kathryn Lowell and Karen Vignare in, MSU Medical Colleges Blended Learning for First Year Science Courses: Uniting Pedagogy to Maximize Experience and Real World Limitations take the reader into Michigan State University's use of blended learning as a vehicle to insure that learning experiences are equivalent for students at three separate campuses. They richly describe how faculty, staff, and administrators meet on a regular basis to discuss working toward a NSF CyberInfrastructure model where all basic science learning experiences are available online. These online resources are coupled with face to face learning as well. Numerous debates occurred on how best to facilitate student learning in multiple locations using new technology tools, recognizing that the goal for students is not only to pass medical board exams but also to acquire life-long learning skills in an ever changing medical and science environment. The authors share the processes used as well as their perspectives on best approaches and strategies in determining what students find effective.

The provocatively titled, Dancing with a Bear: One University's Experience with Evaluating Blended Learning by Patsy Moskal, presents lessons learned at the University of Central Florida when developing 
and conducting a longitudinal impact evaluation. Since 1997, the University has been collecting data on its online and blended learning initiatives and sharing same with faculty, administration, and colleagues in an attempt to validate its investments in instructional technology and to develop a culture of continual improvement and advancement. The title of this article relates to a Russian parable: "When you dance with a bear, you can't quit when you are tired..." Patsy and her colleagues at UCF have been national leaders in sharing their trials and tribulations with other researchers. This article presents many important lessons learned.

Last but by no means least, is The Sloan-C Pillars and Boundary Objects as a Framework for Evaluating Blended Learning by Mark Laumakis, Charles Graham, and Chuck Dziuban. The authors contend that blended learning represents a boundary object: a construct that brings together constituencies from a variety of backgrounds in which each of these cohorts defines the object somewhat differently. The Sloan-C Pillars (learning effectiveness, access, cost effectiveness, student satisfaction, and faculty satisfaction) provide a foundation for the evaluation of asynchronous learning networks that works equally well for the evaluation of blended learning environments. The Pillars and a simplified model of a learning system focus on inputs, processes, and outputs, while providing the framework for a case study of blended learning design and evaluation in a 500 student section of an Introductory Psychology course. The results of a multi-method evaluation of this course indicated very high levels of learning effectiveness and student satisfaction. The article concludes with the suggestion that blended learning may represent a black swan: a high-impact, unpredicted, and rare event that highlights the limitations of our ability to reliably predict the future in any arena, including online learning environments.

In closing, I would like to acknowledge the efforts of a number of individuals who have helped make the Sloan-C Workshop on Blended Learning and Higher Education a success and led to this special edition of JALN. First, without a doubt, credit goes to the leadership of Mary Niemiec and her staff at the University of Illinois-Chicago. They have worked tirelessly to make each of the workshops a success. Second, the members of the Planning Committee for the 2008 Blended Learning Workshop gave unselfishly of their time, namely:

Mary Niemiec, University of Illinois, Chicago, Chair

Chuck Dziuban, University of Central Florida

Bob Fulketh, Golden Gate University

Joel Hartman, University of Central Florida

Bob Kaleta, University of Wisconsin, Milwaukee

George Otte, City University of New York

Anthony G. Picciano, Graduate Center and Hunter College, City University of New York

Karen Swan, Kent State University

Karen Vignare, Michigan State University

Third, there are also several individuals who, by virtue of their dedication, I would also like to acknowledge. First, Kimberly Barba, Janette Salamanca and Emilie Wagner, University of IllinoisChicago, who do a fantastic job of managing all of the details of the workshop. John Bourne and the Sloan Consortium staff especially Katie Fife Schuster, Director of Publications, whose expertise in editing and publication is appreciated by all who work with her. Finally, A. Frank Mayadas, Program Officer at the Alfred P. Sloan Foundation, a visionary and leader who saw earlier than most of us the potential of online learning for our colleges and universities.

The editors of JALN hope our readers enjoy this special issue and welcome any comments.

Anthony G. Picciano, Associate Editor

apicciano@gc.cuny.edu; anthony.picciano@hunter.cuny.edu 